\title{
Típicos tópicos tropicales
}

Juan Francisco Sans

Instituto Tecnológico Metropolitano de Medellín, Medellín, Colombia jfsans@gmail.com
Recepción: septiembre 2019. Aceptación: diciembre 2019.

A Rubén López Cano

\section{Resumen}

La teoría tópica constituye una de las más exitosas y difundidas de la musicología actual. Formulada inicialmente en el seno de la academia de habla inglesa para el estudio del período clásico, su uso se ha extendido a otras escuelas, épocas y estilos musicales. En América Latina se la ha cultivado con asiduidad, dado que permite explicar plausiblemente y con particular eficacia algunos fenómenos propios, como el nacionalismo musical o las complejas fusiones habidas entre el jazz y las músicas locales, de mucha importancia en el continente. El presente artículo procura dar cuenta de algunos de los problemas que se presentan a la hora de aplicar los postulados de la teoría tópica a músicas de un orden diferente para las que fue originalmente concebida, como es el caso de la música latinoamericana en su conjunto. Estos problemas parecen claramente vinculados a la deriva semiótica que con el tiempo fue adquiriendo la teoría tópica. En tal sentido, pretendemos analizarlos y proponer un enfoque distinto a partir de los estudios de Análisis del discurso. Para ello, examinaremos algunos ejemplos concretos donde la teoría -tal como se ha formulado hasta ahora- resulta inoperante; haremos una crítica a lo que hemos llamado "teoría tópica extendida"; examinaremos el tópico musical a la luz de la pragmática y la teoría de la relevancia; y haremos un pequeño ejercicio final que evidencia por qué un tópico no puede ser considerado como un signo, sino una función que deriva de la interacción entre emisores, receptores y texto.

Palabras clave: teoría tópica, semiótica, pragmática, teoría de la relevancia, música latinoamericana
Este trabajo fue leído como ponencia central del XIII Congreso de la Rama Latinoamericana de la Asociación Internacional para el Estudio de la Música Popular, IASPM-AL, en San Juan, Puerto Rico, que tuvo lugar entre el 11 y el 16 de junio de 2018. 


\title{
Tópicas tropicais típicas
}

\section{Resumo}

A teoria das tópicas é uma das mais bem-sucedidas e difundidas da musicologia atual. Inicialmente formulada no seio da academia de língua inglesa para o estudo do período clássico, foi posteriormente estendida a outras escolas, épocas e estilos musicais. Na América Latina, ela é usada com alguma frequência, pois permite explicar de maneira plausível e com particular eficácia, alguns fenômenos de grande importância no continente, como o nacionalismo musical ou as complexas fusões entre jazz e música local. Este artigo tenta explicar alguns dos problemas que surgem ao aplicar os princípios da teoria das tópicas à música de uma ordem diferente para a qual ela foi originalmente concebida, como é o caso da música latino-americana como um todo. Esses problemas parecem claramente ligados à deriva semiótica que, com o tempo, adquiriu a teoria das tópicas. Nesse sentido, pretendemos analisar esses problemas e propor uma abordagem diferente, baseada em estudos de análise de discurso. Para isso, examinaremos alguns exemplos concretos em que a teoria - tal como foi formulada até agora - é inoperante; estabeleceremos uma crítica ao que chamamos de "teoria tópica estendida"; examinaremos a tópica musical à luz da pragmática e da teoria da relevância; e faremos um pequeno exercício final que procura demonstrar a razão pela qual uma tópica não é um sinal, mas uma função que deriva da interação entre emissores, receptores e texto.

Palavras-chave: teoria das tópicas, semiótica, pragmática, teoria da relevância, música latino-americana

\section{Typical Tropical Topics}

\begin{abstract}
The topical theory is one of the most successful and widespread theories of current musicology. Initially formulated within the English-speaking academy for the study of the classical period, its use has been extended to other schools, eras and musical styles. In Latin America it has been cultivated with assiduity, since it allows to explain plausibly and with particular efficiency some typical phenomena of great importance in the continent, such as musical nationalism or the complex links between jazz and local music. This article aims to show some of the problems that arise when topical theory is applied to music of a different nature for which it was originally conceived, as is the case of Latin American music as a whole.
\end{abstract}


These problems seem clearly linked to the semiotic drift acquired by the topical theory. In this sense, we intend to analyze these problems, and propose a different approach based on Discourse Analysis Studies. To do this, we will examine some concrete examples where the theory -as it has been formulated so far- results inoperative; we will also criticize what we have called "extended topical theory"; we will examine the musical topic in the light of pragmatics and the theory of relevance; and we will offer a small final exercise that shows why a topic cannot be considered a sign, but a function that derives from the interaction between emitters, receivers and text.

Keywords: Topical theory, semiotics, pragmatics, relevance theory, Latin American music

\section{Un universo de cisnes negros}

Afirma Paul Feyerabend (2000, XI) que el conocimiento sólo avanza cuando se recurre a hipótesis que contradicen teorías confirmadas y resultados establecidos. Según él, este procedimiento proporciona evidencia imposible de ser obtenida por ninguna otra vía, ya que ninguna teoría es absolutamente consistente con los hechos. Según Feyerabend, el choque entre hechos y teorías representa un claro signo de progreso. Las teorías "se perfeccionan sólo poco a poco, ampliándolas gradualmente para aplicarlas a situaciones que están más allá de su punto de partida" (2000, pp. 79-80).

Atendiendo a lo dicho por este autor, comenzaremos este trabajo examinando cuatro ejemplos de música latinoamericana desde la teoría tópica extendida, entendiendo por tal las derivas semióticas de la teoría tópica original planteada por Leonard Ratner en 1980. Con estos queremos demostrar que, en su estado actual, la teoría extendida resulta insuficiente para dar cabal cuenta de ciertos fenómenos, incluso si se considerasen tales ejemplos como típicos, característicos o modélicos de la teoría. La idea de tópico como signo, que está en la base de la teoría tópica extendida, pareciera erigirse como el principal obstáculo para comprender cómo se construyen los tópicos. Por ello, ofrecemos una revisión crítica de la teoría desde la perspectiva del Análisis del discurso, apelando a la pragmática y la teoría de la relevancia de Dan Sperber y Deirdre Wilson. Luego proponemos un pequeño ejercicio para comprender cómo se construye pragmáticamente un tópico a partir de la interacción entre emisores, receptores y el texto. 
El primer ejemplo lo constituye un pasaje a dos cornos, que Raymond Monelle (2006, p. 83) calificaría sin ambages como un caso típico de lo que los franceses llaman bicinia.

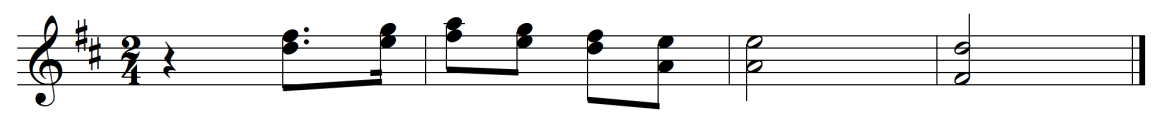

Ejemplo 1.

Se trata de un clásico "movimiento de cornos" (horn motion), o lo que los musicólogos rusos llaman un "paso" o "pasaje de oro". Todo está dado en el texto para reconocerlo como tal: los instrumentos utilizados, el registro en el que se desenvuelven, los giros melódicos, el arreglo armónico, la sonoridad general, etc. No es necesario haber leído las digresiones de Monelle en The Musical Topic para reconocer de inmediato un tópico de caza en este extracto. Se trata pues de un ejemplo de manual. Sin embargo, este pasaje en particular ocurre en un contexto impensable para Monelle: se trata de una frase intermedia del Credo, y del Sanctus, el Benedictus y el Agnus Dei de la Misa en re de José Ángel Lamas, compositor venezolano de finales del período colonial. Resulta altamente improbable que Lamas dedicase esta misa a San Huberto de Lieja, patrono de la caza cuya festividad se celebra los 3 de noviembre, y de la cual Monelle (2006, p. 58) nos brinda algunos ejemplos remarcables en la literatura musical europea donde se utiliza este tópico. En la Caracas de finales del siglo XVIII y comienzos del XIX no existieron iglesias ni cofradías dedicadas a esta advocación. Esta misa la escribe Lamas en una provincia americana de segunda importancia, en el profundamente católico Imperio Español de comienzos del siglo XIX, donde todo el aparataje propio de las cortes francesas y alemanas para la caza -rituales, jerarquías, vestimentas, caballos, sabuesos y cornos de caza- era desconocida. Prácticamente no existió nobleza en la Caracas dieciochesca, que era la clase social que podía realizar esta actividad en tales términos, por lo que uno puede sospechar razonablemente que Lamas no tuvo contacto alguno con el inmenso mundo de referencias al tópico de la caza que Monelle describe en su libro. ¿Cómo vincular entonces el tópico de caza de Monelle con estas frases de la misa caraqueña? ¿No constituiría una sobreinterpretación (Eco, 1997) el identificar ese pasaje como un típico tópico de caza, cuando lo más que podría haber tenido Lamas de la caza en los términos planteados por Monelle, es una experiencia totalmente vicaria? De ser cierta esta conjetura, ¿por qué y para qué utilizó Lamas este recurso en su obra? ¿Qué consciencia tuvo al respecto? ¿A qué auditorio apelaba, si seguramente el mismo estaría tan en la inopia como él con relación a este tópico? Monelle (2006) llega a afirmar que "los cornos en 
Haydn siempre sugieren el campo de caza, incluso cuando simplemente están rellenando la armonía” (p. 7, énfasis nuestro). ¿Imitaba Lamas lo que escuchó en Haydn -abundantemente ejecutado y escuchado en la Caracas de ese entonces, y paradigma de los compositores latinoamericanos de comienzos del XIX-ignorando los referentes de este tópico? ¿Podemos decir entonces que usó un tópico "destopicalizado"? Y si tenía conciencia del mismo, ¿de dónde los sacó para saber que esto era un "tópico de caza", en un medio tan desprolijo como era la Caracas de comienzos del siglo XIX? ¿Cómo es entonces posible que un tópico, a pesar de estar tan mal usado como en este caso, siga funcionando tan bien, y siga evocando en los oyentes "competentes" ${ }^{1}$ de hoy lo que la teoría dice que debe evocar?

Examinemos un segundo ejemplo de este mismo tópico, pero esta vez de mediados del siglo XX, compuesto siglo y medio después de Lamas. Se trata de la "Canción con tarde y con niños", que forma parte de las 17 piezas infantiles del compositor nacionalista venezolano Antonio Estévez. Encontramos allí el uso franco de un "llamado de caza" (hunting-horn call) en la mano derecha del piano.
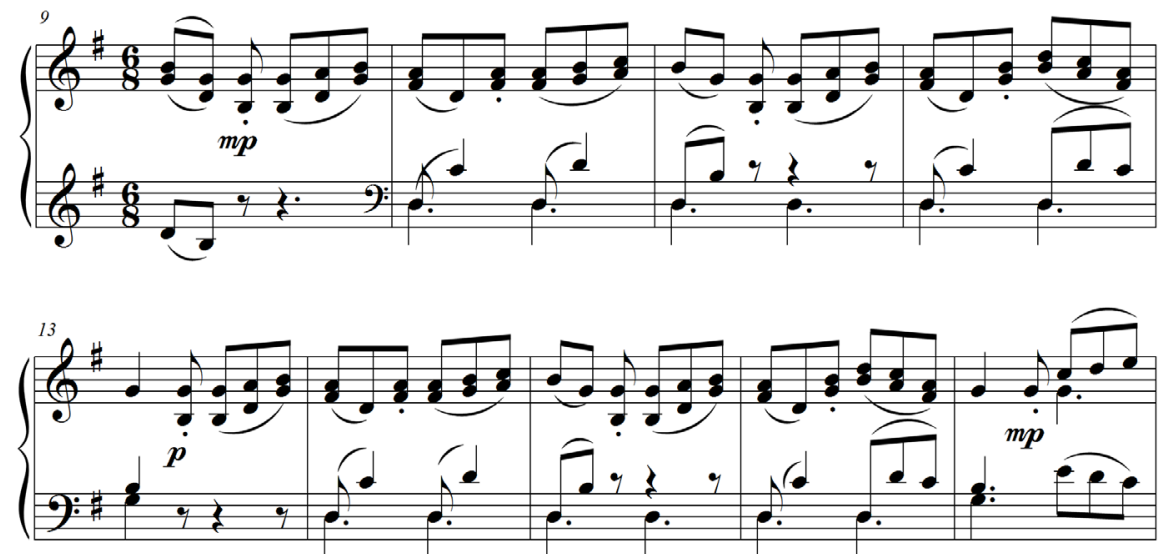

Ejemplo 2 .

Como afirma Monelle (2006), “el efecto del 'movimiento de cornos' es suficientemente distintivo para ser reconocible incluso en la ausencia del timbre del corno"2 (p. 98), algo que resulta obvio en esta pieza para piano. No obstante, y a pesar de que la tarea para Monelle estriba en "buscar manifestaciones del tópico de caza en la música sin ninguna referencia

\footnotetext{
${ }^{1}$ En la teoría tópica extendida suele hablarse de oyentes "competentes" para referirse a aquellos emisores y receptores capaces de generar y comprender tópicos "bien formados". Tal concepto deriva de los términos actuación y competencia de la gramática generativa de Noam Chomsky.

2 "The effect of 'horn motion' is sufficiently distinctive to be recognizable even in the absence of horn timbre". La traducción es nuestra.
} 
específica a la caza en un título pintoresco o en un texto"3 (p. 98) resulta absolutamente forzado en este contexto que -de los 25 compases de esta miniatura musical infantil- nueve estén dedicados a un tópico de este tipo. ¿A qué viene la evocación de un acto tan violento como la caza, en la tarde cantarina e infantil que nos sugiere el título de la obra? ¿Cómo explicamos la presencia de este tópico en un contexto tan contrastante? Porque una cosa es que no haya referencias específicas a la caza en títulos o textos en la partitura de una pieza abstracta, como una sinfonía o una sonata; pero otra es que esos títulos o textos sean francamente contradictorios o absurdos respecto del tópico, como es el caso. Insistimos en que la pregunta sería por qué sigue funcionando el tópico en este caso para los oyentes "competentes".

De Antonio Estévez es también una obra maestra del nacionalismo musical venezolano: la Cantata criolla (1954). Esta cantata utiliza como tema central las notas iniciales de la secuencia Dies Irae del oficio de difuntos.

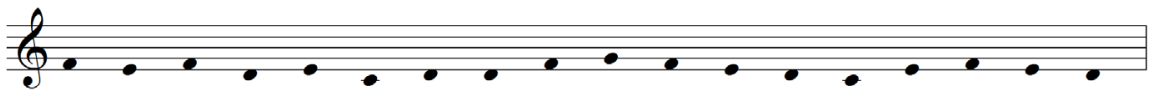

Ejemplo 3.

El fragmento tiene una larguísima tradición como cita musical, asociada siempre a la muerte, al infierno y al demonio, y así lo utiliza efectivamente Estévez al evocar el duelo musical en un joropo, entre el cantante Florentino y el diablo. ${ }^{4}$ Uno de los primeros ejemplos conocidos de la utilización de esta cita es la introducción de la Sinfonía no 103 "Redoble de timbal" de Joseph Haydn, con asociaciones evidentes a la guerra y a la muerte. También la utilizan en este mismo sentido Héctor Berlioz en su Sinfonía Fantástica op. 14; Johannes Brahms en la sexta pieza del op. 119 para piano; Peter Illich Tchaikowsky en su Sinfonía Manfredo; Franz Liszt en su Totentanz para piano y orquesta; Gustav Mahler en la Sinfonía No. 2 "Resurrección"; Giacomo Puccini en Tosca; y Sergei Rachmaninov en muchas de sus sonatas, preludios y estudios para piano, sus sinfonías y su Rapsodia sobre un tema de Paganini, por mencionar sólo casos muy relevantes. En fin, se trata de un recurso musical utilizado siempre con un sentido muy particular, con una muy larga historia.

\footnotetext{
3 "It is our task, then, to seek manifestations of the hunt topic in music without any specific reference to hunting in a picturesque title or text”. La traducción es nuestra.

${ }^{4}$ A este duelo se le suele llamar "contrapunteo", y consiste en que los cantantes deben tomar siempre la última copla que deja el contrincante para responderle. Aquel que falle en versificar, pierde. En este caso, pierde el alma.
} 
Muchos teóricos son reticentes a considerar las citas como tópicos musicales en sentido estricto. Kofi Agawu (2012, p. 96) recomienda distinguir los tópicos de las citas y alusiones musicales, remitiendo estas últimas a un estudio completamente independiente. Por su parte, Monelle (2006, pp. 165-166) define las citas literales como "cuasi-tópicos" o "proto-tópicos", considerándolas "ejemplos pobres" de tópicos musicales, aunque debe admitir que las figuras de caza -que ha estudiado profusamente en tanto tópicos- "constituyen a menudo citas, o casi citas, de llamadas de caza reales [...]" (p. 166), ${ }^{5}$ con lo cual deja muy clara la diferencia entre citas y tópicos. Rubén López Cano (2005, p. 5) distingue entre citas, parodias, tópicos y alusiones musicales como procesos intertextuales diferentes, dando al tópico la preeminencia como estrategia analítica más eficiente en el estudio de la semiosis musical. Pero son quizá quienes han aplicado la teoría al nacionalismo musical latinoamericano, los que más han insistido en esta diferenciación entre citas y tópicos, puesto que la exégesis tradicional del nacionalismo ha fincado siempre sus esfuerzos en la cita como recurso expresivo básico sin mucho éxito hermenéutico. Por ejemplo, para Melanie Plesch, el tópico es "mucho más que una cita, es una idea recurrente acerca de una danza, canción, instrumento, sistema musical, etc., que atraviesa todo el repertorio nacionalista apareciendo ya en posición temática, ya en posición descentrada, tanto en composiciones con títulos homónimos [...] como en otras denominaciones genéricas" (2008, p. 40). En el caso que nos ocupa, Estévez no sólo cita el Dies Irae, sino que además, lo hace en ritmo de joropo. Estaríamos hablando entonces no ya de uno, sino de dos tópicos funcionando simultáneamente. 0 sea, se trata de un tópico topicalizado: la cita del Dies Irae constituye un tópico que se vehicula a través del joropo, que -siguiendo a Ratner-fungiría a su vez como tópico de género o estilo dentro de la Cantata criolla. Pero los mundos en los que ambos tópicos funcionan -el clásico y el folklórico- son musicalmente inconmensurables entre sí. Se trata pues de un manejo muy poco convencional del tópico musical como lugar común.

El último ejemplo que examinaremos se refiere a una obra de Teresa Carreño. Ella escribe la fantasía-capricho Un bal en rêve op. 26 para piano en la segunda mitad del siglo XIX. La compositora-pianista ha abandonado su Venezuela natal a los ocho años de edad, por lo que esta pieza constituye una nostálgica reminiscencia musical de la ciudad de Caracas donde se crió. Luego de una larga introducción de 18 compases, la pieza prosigue con un pasaje cantabile muy tranquilo, en el llamado singing style,

5 "Ringer shows that 'hunting' figures are often quotations, or near quotations, from actual hunting calls, of which many collections have survived". 
asociado con un dormir plácido, indicado explícitamente en la partitura con la expresión Le sommeil. ${ }^{6}$ En el compás 53, el lírico descanso es interrumpido por el recuerdo de un agitado baile, indicado en la partitura con la expresión Le rêve.
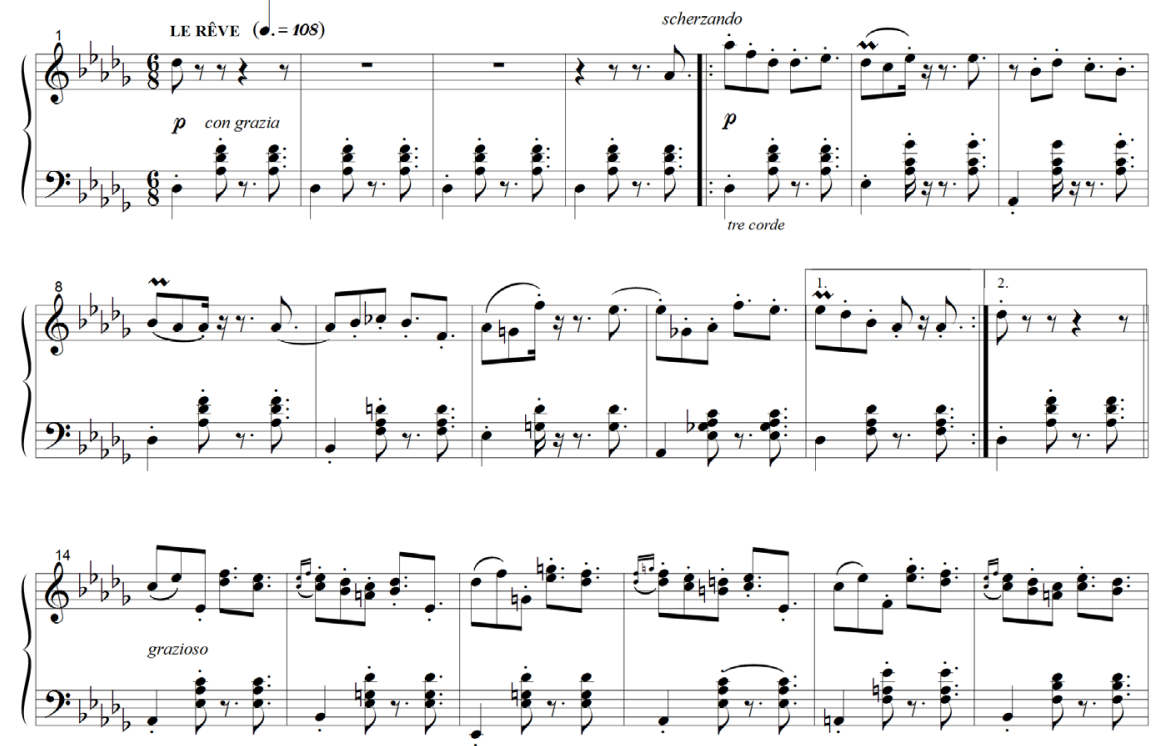

Ejemplo 4 .

Sabemos que se trata del baile al que hace referencia el título de la obra, porque utiliza materiales musicales característicos de uno de los géneros más idiosincrásicos de la época: el merengue caraqueño, conocido entonces como danza. Tenemos todos los elementos del merengue presentes en este trozo: compás binario en tiempo rápido, melodía dividida en dos grupos (uno de tres corcheas y otro de dos corcheas con puntillo), acompañamiento con ritmo de tango, frases cuadradas, etc. Para Danuta Mirka, los tópicos musicales son "estilos y géneros musicales tomados fuera de su propio contexto y usados en otro" (2014, p. 2), ${ }^{7}$ por lo que la interpolación de este trozo a lo interno de una fantasía habría que tratarla como un caso modelo de tópico. El verdadero problema que se presenta aquí, es que Carreño está ofreciendo esta obra a una audiencia europea, siendo como fue publicada por Heugel en París, como tantas otras piezas suyas. Como bien plantea Mirka, la cuestión estribaría en saber "primero, si un estilo o género dado era o no reconocido por los escritores contemporáneos;

${ }^{6}$ El trozo sugiere una cita del Happy birthday, aunque de ello no hay evidencia alguna más allá del parecido de las notas iniciales de las dos primeras frases de la melodía, por lo que no pasa de ser una simple coincidencia.

7 “[...] musical styles and genres taken out of their proper context and used in another one." La traducción es nuestra. 
segundo, si era o no reconocido en otros contextos, mezclado con otros estilos y géneros" (2014, p. 3). ${ }^{8}$ En otras palabras, como dice Agawu, "los tópicos se reconocen sobre la base del conocimiento previo" (2012, p. 83), pero este no parece haber sido el caso del merengue caraqueño para las audiencias francesas del XIX. Por eso, Agawu concibe los tópicos musicales como "lugares comunes incorporados a los discursos musicales y reconocibles por miembros de una comunidad interpretativa" (2012, p. 30). Para la comunidad interpretativa destinataria de esta obra, el merengue estaba muy lejos de ser un lugar común, por lo que no significaba nada más allá de su contenido estrictamente musical, al no conocer de antemano su historia ni los elementos constitutivos del género al que el tópico alude. Un tópico sólo existe para el receptor si éste lo puede identificar, es decir, si posee competencia sobre el mismo, una condición básica para que pueda ser percibido y explicitado verbalmente (McKay, 2007, p. 166, v. nota 1). La acción del tópico queda así anulada al no poderse activar en el oyente ninguna referencia al mismo. Seguramente los franceses decimonónicos se quedaron perplejos al escuchar esta pieza, y la recibieron inevitablemente como un caso de música pura, aunque la utilización de ritmos exóticos haya podido llamar su atención de algún modo, convirtiendo así un tópico potencial (un lugar común) en un tropo (una figura de excepción).

La pregunta en los últimos dos casos, es si podría considerarse que el tópico puede existir como algo independiente de los emisores y receptores, esto es, si se trata de un elemento sígnico, inherentemente textual. Si así fuese, la competencia de emisores y receptores sería independiente del texto, y explicaría por qué Lamas o Estévez pueden escribir un llamado de cornos sin relación alguna con el universo de tópicos, haciendo los signos independientes de sus interpretantes. Pero esto nos regresaría de plano a la idea de la música absoluta del siglo XIX y a la autonomía de la obra musical, algo que estamos seguros no está en la intención de ningún musicólogo actual.

Hemos planteado estos cuatro ejemplos para mostrar cómo la aplicación de la teoría tópica a casos, circunstancias y contextos en los cuales sus desarrolladores iniciales no pensaron jamás, saca a la luz falencias y debilidades metodológicas y conceptuales. El problema es que todas estas disquisiciones que hacemos se concentran sin excepción -para hablar en términos de Jean-Jacques Nattiez (1990)- en los elementos propios del

\footnotetext{
${ }^{8}$ Hablando de Monelle, dice que "If topics are styles and genres used out of their proper context, the question of the historical basis of topic theory splits into two different but interrelate questions: first, whether or not a given style or genre was recognized by contemporary writers; second, whether or not it was recognized in other contexts, when mixed with other styles and genres".
} 
material musical, es decir, en el texto considerado como nivel neutro o inmanente, pero no interpela los procesos poiéticos y estésicos, en cuya interacción se genera propiamente el tópico. La teoría tópica extendida da por sentado que el tópico va a ser reconocido o no por el oyente, por cuanto es un signo, y de que si este lo reconoce, lo va a usar como guía de la interpretación (McKay, 2007, p. 170). Es decir, la comunicación entre emisor y receptor es algo dado, si ambos están en posesión del código. Pero rara vez se plantea con seriedad qué sucede cuando el tópico concebido como signo, no es reconocido por el emisor y/o el receptor, como planteamos en los cuatro ejemplos ofrecidos. El caso es que esta circunstancia no es la excepción que confirma la regla. El emisor puede recurrir al tópico como recurso compositivo, pero eso evidentemente no basta para que se concrete la comunicación. Para ello debe procurar la emisión del tópico a través de su instanciación material en partitura o sonido, y esta instanciación puede ser malintencionada, fallida, débil, incluso insuficiente por falta de habilidad del emisor. Puede darse el caso de que un oyente competente detecte un tópico musical cuando el emisor no ha pensado en lo más mínimo en ello, como podría ser el caso de Lamas o Estévez antes mencionado. Estos son los cisnes negros que la teoría tópica extendida no explica. El que existan cisnes negros en una teoría no desdice de manera absoluta de la hipótesis "todos los cisnes son blancos": en todo caso, la matiza. Habría entonces que formularla así: "no todos los cisnes son blancos. Hay algunos negros". Trataremos de explicar cómo vuelan los cisnes negros en el próximo aparte.

\section{En busca del tópico perdido}

Cuando Ratner formuló por primera vez el concepto de tópico musical (1980), dio a luz una formidable idea en la convulsionada musicología de la década de los años ochenta. Anteriormente a Ratner, nadie había reparado en las innumerables referencias cruzadas que pululaban en las obras maestras europeas del siglo XVIII, ni a sus vínculos con la sociedad. Mirka (2014, p. 1) equipara este hallazgo con la conmoción causada por el descubrimiento de los colores en los frisos del Partenón de Atenas, después de milenios en los cuales se creyó que eran del color del mármol en que fueron esculpidos.

Los tópicos musicales carecen del fundamento histórico que Ratner pretendió encontrar en la teoría musical del siglo XVIII (Monelle, 2000, pp. 
24-28). ${ }^{9}$ No obstante, su uso como herramienta heurística brindó una alternativa plausible y luminosa al análisis musical, que para ese entonces estaba siendo objeto de fuertes cuestionamientos por parte de la New Musicology (Kerman, 1980 y 1985). Esta tabla de salvación animó a los seguidores de Ratner no sólo a profundizar en la idea del tópico musical, sino a intentar extender su aplicación a la música del siglo XIX. Comienzan entonces a producirse arreglos, ajustes y reacomodos en la teoría original. Mirka (2014, pp. 1-2) advierte que el planteamiento inicial de Ratner se fue desdibujando a medida que se fueron añadiendo más y más elementos al llamado universo de tópicos. Precisamente, una de las tareas centrales de la teoría tópica estriba, según Agawu (2012, p. 84), en construir tal universo de tópicos desde sus mismas bases. Muchos de los seguidores de la teoría en Latinoamérica, entre los que encontramos a Melanie Plesch (1996, 2008, 2012, 2014, 2017a y 2017b), Acacio Piedade (2011 y 2013), Oscar Hernández Salgar (2013), Omar Corrado (2017), Paulo de Tarso Salles (2017) y Claudia Fallarero (2018), se han dedicado a esto.

Es así como el concepto original de tópico musical se fue haciendo cada vez más complejo, impreciso y evanescente en la medida en que se alejaba de su objeto de estudio inicial -el Barroco tardío y el Clasicismo del siglo XVIII europeo- al punto que uno de los problemas más acuciantes de la teoría actual radica en precisar en qué consiste en definitiva un tópico musical. Y es que con la teoría tópica parece ocurrir lo mismo que con otras teorías musicales: al intentar ampliar su radio de acción más allá de los repertorios, las regiones geográficas y el tiempo histórico para los cuales fueron diseñadas, comienzan a hacerse inconsistentes. Eso ha sucedido con teorías consolidadas como el neoschenkerianismo, la postonalidad, el neoriemanianismo, el análisis paradigmático, la teoría transformacional, la tripartición, la teoría generativa de la música tonal o el análisis pantonal de Reti, por lo que han sido virtualmente ignoradas por la musicología latinoamericana. Pero la teoría tópica ha gozado de una larga y vehemente acogida en el continente, y sus aplicaciones a casos regionales (principalmente del siglo XX) se siguen multiplicando a través de artículos, estudios monográficos, conferencias y tesis. Mirka (2014, p. 1) asegura que su éxito deriva precisamente de la facilidad que ofrece para una verificación intersubjetiva de sus resultados -cosa que no ocurre con el resto de las teorías analíticas- lo que brinda a musicólogos, intérpretes y oyentes una inmensa satisfacción y estímulo para seguirla utilizando.

${ }^{9}$ Esto ha contribuido a una constante confusión entre los tópicos y las figuras retóricas musicales de la Doctrina de los afectos, que sí fueron efectivamente objeto de la teoría musical dieciochesca. 
Autores posteriores a Ratner, como Agawu (1991, p. 128), Monelle (2006, p. 28) o Robert Hatten (1994), comienzan a concebir el tópico ya no simplemente como un "sujeto del discurso musical" (Ratner 1980, p. 9), sino como un signo, inscribiendo la teoría en el ámbito de la semiótica. Habría que admitir de entrada que, si bien esto le ha dado prestigio científico a la teoría, en realidad no ha ayudado demasiado a develar la naturaleza real de los tópicos, y más bien ha limitado la discusión a dilucidar sin mucho éxito los mismos problemas planteados a comienzos del siglo XX por Ferdinand de Saussure y Charles S. Peirce, pero en el campo musical. Términos como "signo", "significante”, "significado", "interpretante”, "icónico", “simbólico", “indexical”, “connotación”, “denotación”, etc., atiborran los textos de la teoría tópica post-ratneriana sin aportar nada demasiado útil por esclarecer el asunto. En nuestra opinión, esto ocurre porque la semiótica es una teoría fundamentada en el modelo del código, donde la comunicación se concibe básicamente como un proceso de codificación y decodificación de mensajes. El que la teoría tópica haya tomado este camino resulta relativamente sencillo de comprender, teniendo en cuenta que:

La idea de que la comunicación se consigue codificando pensamientos en forma de sonidos está tan arraigada en la cultura occidental [desde la época de Aristóteles] que resulta difícil considerarla como una hipótesis, y no como un hecho. Y, sin embargo, el modelo del código de la comunicación verbal no es sino una hipótesis, con méritos bien conocidos y no tan bien conocidos defectos (Sperber y Wilson, 1994, p. 17).

Así, a nuestro entender, el principal defecto de la teoría tópica actual no es otro que el señalado por Sperber y Wilson para la semiótica: resulta descriptivamente insuficiente para explicar la comunicación musical, dado que la comprensión implica algo más que la simple codificación y decodificación de una señal. Aclaremos que esto no invalida en absoluto a la teoría tópica en tanto tal: invalida en todo caso a la semiótica como el único método posible de aplicar a la teoría. Parafraseando a Sperber y Wilson (1994, p. 20), si la música utiliza códigos (como efectivamente los usa), se produce un inexplicable vacío entre la codificación de los sonidos, y los pensamientos y emociones efectivamente comunicadas por éstos. El problema es que este vacío no se llena con más codificación.

Es probable que de ahí derive la inquietud de López Cano cuando se pregunta “¿qué es un tópico, un trozo de competencia intertextual, un signo o una clase de hipersigno? ¿En qué se distingue de otros signos musicales? ¿Una semiótica orientada cognitivamente debe conformarse con la 
concepción de tópico como signo?" (2002, p. 13), para responderse de seguido: "la concepción del tópico tiene que ver con ese punto cognitivo en el que el escucha (o músico) competente comienza a construir mundos específicos con el objeto sonoro, gracias a la articulación de marcos y guiones que orientarán su semiosis musical” (p. 13). López Cano (2002, p. 24) está conteste del problema cuando propone una semiótica de extracción cognitivista que trascienda las explicaciones fundadas exclusivamente en códigos y procesos de codificación. Pero el vacío tampoco se llena aplicando el concepto de competencia a la teoría tópica (Hatten, 1994) -tomado prestado de la gramática generativa de Noam Chomsky- puesto que obliga al receptor a conocer de antemano el significado de los signos para poder decodificarlos.

Si hay algo característico en la comunicación, es precisamente la incompetencia. Pensemos por ejemplo en las nuevas generaciones, cada vez más alejadas culturalmente hablando del universo de tópicos de Agawu, Monelle o Hatten. ¿Creemos que esas personas, sin ningún tipo de entrenamiento en la escucha de música clásica, pueden ser consideradas como oyentes competentes de estos tópicos? ¿Cómo harán para decodificar los signos que no conocen? Lo interesante es cómo, a pesar de la incompetencia, los seres humanos siguen comunicándose de algún modo entre sí. ¿Cómo desentrañar esta aparente paradoja? Si como admite López Cano (2002, p. 16, siguiendo a Umberto Eco), el tópico musical constituye básicamente un recurso pragmático, ¿por qué insistir entonces en una semiótica como una solución para la teoría? ¿Por qué no adscribirlo de una vez por todas a la pragmática, y más específicamente, a la agenda del Análisis del discurso?

La comunicación no se produce cuando el emisor codifica un mensaje y el receptor lo decodifica. De hecho, emisor y receptor podrían no tener elementos suficientes y necesarios para ello, como cuando las audiencias francesas desconocen el merengue caraqueño como género inserto en la fantasía para piano de Teresa Carreño, y son por tanto incapaces de decodificar tal signo; o cuando Lamas desconoce los referentes del paso de oro, y sin embargo, insiste en utilizarlo en su misa. Cuando la intención comunicativa del emisor logra llamar la atención del receptor, éste asume de hecho que el emisor está intentando comunicarse con él, y que para ello está cumpliendo ciertas normas básicas. Paul Grice (2000 [1957]) llama a este proceso el principio de cooperación, que funciona con base en las inferencias que hacen los interlocutores sobre las intenciones mismas de comunicarse. El emisor aporta pruebas de querer comunicarse y el receptor responde a esta intención cuando obtiene pruebas efectivas del emisor de que la comunicación va a ser relevante. Por el principio 
de cooperación, emisor y receptor aceptan antes que nada comunicarse, porque entienden que tienen algo relevante que decir y que oír. El tópico se genera cuando ambos le otorgan sentido a la emisión. Este sentido se basa en las inferencias hechas por emisores y receptores al momento de comunicarse, y va a depender del conjunto de supuestos que activan para interpretar un enunciado, lo que suele conocerse en el Análisis del discurso como contexto (Escandell Vidal, 1996, p. 118). El proceso de inferencia es deductivo, pero no necesariamente obedece a la lógica formal:

Y es que la comprensión, como otros mecanismos cognoscitivos, funciona por medio de razonamientos heurísticos no enteramente falseables: en primer lugar, porque el destinatario no tiene una certeza absoluta sobre la intención comunicativa del emisor, sino que debe construir una hipótesis; en segundo lugar, porque, incluso en las mejores condiciones posibles, el destinatario puede no acertar con esa intención comunicativa; y, en tercer lugar, porque, incluso habiendo deducido correctamente cuál es la intención comunicativa, puede construir su inferencia sobre unos supuestos equivocados y llegar a una conclusión inadecuada (Escandell Vidal, 1996, pp. 114-115).

Precisamente por eso, la propuesta de Grice se conoce como modelo inferencial -muy distinta al modelo de código- que sin duda nos parece más adecuada para describir cómo funcionan los tópicos en la comunicación musical real. Cuando Agawu propone inventariar el universo completo de tópicos como tarea fundamental de la teoría tópica; o por el contrario, cuando Monelle hace una descripción exhaustiva de cada uno de ellos (dedica todo un libro -The Musical Topic- para describir apenas tres de ellos: el pastoral, el militar y el de caza), se hace evidente lo quimérico de ambas empresas, así como su falta de sentido común. Según el modelo inferencial, un tópico es el resultado de un complejo proceso entre emisores y receptores, donde se activan una serie de supuestos entre un gran conjunto de supuestos posibles. Siendo así, dar cuenta de un universo de tópicos como propone Agawu sería como intentar conocer a priori todos los supuestos sobre los se van a basar las inferencias de receptores y emisores, lo cual luce imposible. Describir en detalle todos los conocimientos enciclopédicos asociados a cada tópico, como pretende Monelle en su libro, es pretender dar cuenta de todas las hipótesis interpretativas posibles que uno de esos tópicos puede desatar en receptores y emisores. Pero como hemos demostrado en el caso de la llamada de cornos en Lamas y Estévez, tal exhaustividad no es posible, porque siempre habrá supuestos no previstos o contemplados. Desde el punto de vista del procesamiento cognitivo, cualquiera de las dos operaciones resulta absolutamente 
antieconómica para una efectiva comunicación: "el problema no es que sea difícil aportar hipótesis sobre qué podría haber querido transmitir el emisor: el problema es que hay demasiadas hipótesis posibles" (Sperber y Wilson, 1994, pp. 47-48). Por eso, las ambigüedades, las ambivalencias, los malentendidos son moneda común en la comunicación verbal: ¿por qué habría de ser diferente en la comunicación musical? La pragmática propone por tanto dar cuenta, no del contenido de las hipótesis interpretativas en sí, sino de cómo los interlocutores escogen las hipótesis (correctas o no, apropiadas o no) entre un repertorio indefinido de hipótesis. Esto resulta posible precisamente por el principio de cooperación: cuando los emisores observan las normas, y cuando los receptores esperan que aquéllos las observen, resulta factible descartar inferencialmente toda una serie de interpretaciones de cualquier tópico concreto, reduciendo al mínimo los costos de procesamiento y permitiendo así la comunicación efectiva (Sperber y Wilson, 1994, p. 26).

En aras de obtener un máximo efecto cognitivo con un mínimo esfuerzo de procesamiento, los interlocutores calculan únicamente aquellos supuestos que les brindan la garantía de mayor relevancia, es decir, aquellos con implicaciones no triviales. Este proceso sólo se activa si el emisor ha hecho ostensible su intención comunicativa a través de un estímulo (sonoro, visual, gestual, gráfico) y ha logrado captar efectivamente la atención del receptor. Esto es lo que Sperber y Wilson (1994, p. 67) llaman conducta ostensiva. La sola intención de comunicarse brinda un estímulo mutuamente manifiesto al emisor y al receptor que da garantía de relevancia a lo que se va a comunicar. Lo importante de este modelo es que la comunicación ostensiva tiene fuertes implicaciones sociales, porque normalmente el emisor está interesado en conocer si su estímulo ostensivo ha funcionado, y el receptor en hacer saber que ha sido aludido por ese estímulo, que está prestando atención, que comparte los supuestos del emisor, y que por tanto está colaborando en la comunicación. Un emisor que utiliza intencionalmente un tópico musical aspira a que su audiencia lo reconozca, independientemente de cómo ocurre la instanciación textual del mismo. Pero ese reconocimiento no tiene necesariamente por qué ocurrir, o puede ocurrir de manera imprevista, equívoca o sin relación con las aspiraciones del emisor. Y si un receptor reconoce un tópico musical, usualmente se activa en él una sensación de que comprende el estímulo, y da muestras ostensibles de ello de algún modo (asintiendo, rechiflando, aplaudiendo, palmeando, coreando, comunicándolo verbalmente, meciéndose al son de la música, etc.). Este proceso sólo va a ocurrir si la información le resulta relevante. Cuando reconocemos en Lamas y Estévez el llamado de cornos, o cuando nos percatamos de que Estévez está haciendo uso del Dies irae en 
ritmo de joropo, entramos en sintonía con lo plasmado en el texto musical, independientemente de las intenciones ilocutivas de los compositores y el universo de referencias sobre el cual basan sus supuestos. Lo importante es que activan los supuestos del receptor. Se establece, para bien o para mal, la comunicación musical. De esta interacción nace el tópico musical.

Por tales motivos, Sperber y Wilson bautizaron a este proceso como el principio de relevancia, de inmensas consecuencias para la pragmática, y por supuesto, para los tópicos musicales. Para Sperber y Wilson, "todo acto de comunicación ostensiva comunica la presunción de su propia relevancia óptima" (1994, p. 198). Eso significa que un conjunto de supuestos, enunciados por un emisor a través de un estímulo ostensivo, puede o no ser lo suficientemente pertinente y relevante como para que el destinatario presuponga que vale la pena procesarlo. La relevancia no es por tanto una propiedad de los enunciados en sí, sino que se establece en la relación entre enunciados, contexto de emisión y de recepción: “Lo que puede ser relevante para alguien en un momento dado, puede no serlo para otra persona, o puede no serlo para él mismo en otras circunstancias" (Escandell Vidal 1996, p. 120). Para ilustrarlo, pongamos el caso de un toque de diana militar ejecutado con una trompeta. Su enunciado musical podrá ser exactamente el mismo en diferentes contextos de emisión, pero su procesamiento variará de acuerdo a los supuestos de quienes emiten y reciben tal señal, y las circunstancias en que ello ocurre. No será igual de relevante escuchar esa misma diana en un concierto, en una retreta, en un cuartel, en una batalla, en una parada o en una obra teatral. Tampoco lo será si quien la escucha es soldado, oficial, espectador, actor o público. Y su relevancia cambiará dependiendo de quien la emita: si es el trompeta mayor, si es el principal de una sinfónica o de una banda, o si es un músico de foso. Tal emisión no constituye en sí misma un tópico musical, porque el tópico es una función que ocurre en determinadas interacciones.

Para que la relevancia comunicativa ocurra, tiene que haber una intención ostensible de comunicar. Si una persona hace una seña con la mano a otra para que se acerque a él, el receptor puede evaluar el contexto y decidir si va o no a prestar atención, si se acerca o no, si se expone a que lo roben o no. Por eso, para Escandell Vidal "cualquier acto de comunicación comunica automáticamente una presunción de relevancia” (1996, p. 121), es decir, si alguien dice algo, es porque quiere ser escuchado. Pero eso no garantiza que lo sea. Si bien el estímulo ostensivo pueda ser el más relevante que un emisor utiliza para comunicar su conjunto de supuestos, eso no implica que produzca necesariamente estímulos óptimamente relevantes en el receptor. En otras palabras, el emisor aspira a que el receptor crea que 
es relevante, pero el receptor no tiene por qué darse por aludido en este sentido. Sperber y Wilson inauguran con la teoría de la relevancia un tercer modelo de comunicación inscrito en el corazón mismo de la pragmática: el modelo ostensivo-inferencial, precisamente porque consideran que la comunicación es posible incluso con la sola ostensión, sin intervención de códigos ni inferencias. Pensamos que este modelo podría explicar mucho mejor que la semiótica el problema de los tópicos musicales.

\section{El tópico musical desde la perspectiva pragmática}

Visto lo anterior, podríamos concebir el tópico musical, más que como un signo, como una función, observable en todos los niveles de la estructura textual. Tomlin y otros (2000, p. 142) consideran que existen al menos tres niveles de tópicos: 1) de nivel global o discursivo; 2) de nivel episódico o párrafo; 3) de nivel local o clausal. Los tipos de Ratner están vinculados sin duda con los tópicos del nivel global. Van Dijk (1995, p. 151) llama a estos tópicos la macroestructura de un texto, definida como "la proposición subyacente que representa el tema o 'tópico' de un texto y constituye la síntesis de su contenido" (Calsamiglia y Tusón, 1999, p. 225). Por eso, en el Análisis del discurso se suele considerar el tópico como aquello de lo que se habla en un texto. ${ }^{10}$ El tópico de nivel global o macroestructura podría definirse como la memoria que nos queda en la mente después de haber interactuado con un texto y constituye su nivel más comprehensivo. Se expresa a menudo a través de un título, un encabezado o un resumen. Si preguntamos “¿Qué tocó hoy la orquesta?” y nos contestan “Una fuga”, nos haremos de inmediato una representación mental de la misma sin haberla siquiera escuchado, de acuerdo con los supuestos que se activen sobre el particular. Pero la idea de "fuga" que cada quien se hace en las diferentes situaciones comunicativas puede ser muy distinta.

Podemos equiparar lo que Ratner llama estilos al tópico episódico y al tópico clausal, es decir, a los tópicos que están por debajo de la macroestructura. Los tópicos de este nivel coadyuvan entre sí para darle coherencia general al texto en su conjunto. En la medida en que discurre la música, el receptor se va creando expectativas y formulando hipótesis interpretativas (anafóricas y catafóricas) sobre estos tópicos, que van siendo o no corroboradas en el texto, y que en la medida en que se hacen recursivas terminan generando una macroestructura en el receptor o, si se quiere, un

\footnotetext{
${ }^{10}$ En la literatura sobre pragmática se le llama también tema, que evitaremos aquí para no confundirnos con la larga tradición que esta palabra tiene en el análisis musical formal.
} 
macrotópico. En estos niveles bajos, los tópicos suelen estar vinculados a la información dada en un discurso, en contraste con la información nueva. A esta dualidad entre información dada e información nueva se la conoce como tópico y comento, tema y rema, presuposición y foco, o presuposición y aserción. Para Van Dijk (1995, p. 180), el tópico se asocia a menudo con lo que el oyente ya sabe, con lo que el emisor presupone va a ser identificado por el receptor, y suele presentarse de primero en la línea temporal del discurso; el comento se suele asociar con lo no sabido por el receptor, y suele presentarse posteriormente. Por eso, al tópico se lo considera a menudo como el elemento con más bajo dinamismo en la comunicación, el lugar común, en tanto que el comento requiere de un mayor procesamiento cognitivo. Resulta esencial para el emisor colocar al receptor en su propia perspectiva, basándose en "algo presente y conocido para alcanzar algo que está menos presente o es más desconocido" (Tomlin y otros, 2000, p. 138). En el examen de estas funciones interesa identificar tanto el tópico como el comento, cuándo y dónde se producen cambios de tópico, cómo ocurren esos cambios, y cómo se generan los efectos contextuales, algo que la teoría tópica extendida no ha abordado hasta el presente. Resulta por tanto muy importante definir a qué nivel se están observando los tópicos en el discurso musical. Las emisiones de un nivel dado se topicalizan si permiten a emisores y receptores organizar la estructura conceptual del discurso musical, jerarquizar la información, activar la memoria y optimizar el procesamiento cognitivo. Como se ve, estos procesos no son de naturaleza estrictamente musical, sino más bien de carácter psico-social. El discurso musical se genera entonces en la interacción social (como todo discurso), y no en los signos musicales en sí mismos.

Los tópicos musicales del nivel global son muy importantes, pues de ellos depende la coherencia del discurso musical. Si el texto musical brinca de tópico en tópico en el nivel clausal o episódico, y entre ellos no contribuyen recursivamente a construir un tópico global, el discurso podría resultar cohesivo (como en el caso de los potpurrís), pero no necesariamente coherente. El tópico musical global funciona como un organizador que sirve de marco cognitivo para la comprensión del discurso musical. De ahí la importancia de los títulos, los aires, los géneros, que contribuyen activamente a generar las hipótesis interpretativas que hacen los receptores, y que enmarcan su comprensión. Pero no debemos olvidar que es el emisor quien selecciona el tópico según las inferencias que elabora acerca del receptor previsto de un texto, y es el receptor quien lo procesa (Bolívar, 1998, p. 250). Por tanto, son los emisores y los receptores quienes topicalizan las emisiones musicales, no los textos. Por eso resulta impreciso decir que una llamada de cornos es un tópico de caza, una siciliana 
un tópico pastoral, o un toque de corneta con redoblante alla marcia un tópico militar, sin determinar antes qué supuestos activan estas emisiones al interactuar con receptores y productores. El tópico musical no será por tanto el texto, sino su efecto contextual, entendido el contexto como los supuestos activados en una situación comunicacional dada. Además, el tópico musical no es algo claramente delimitado como una frase, periodo o estructura musical dada, sino que depende del grado de definición activado por las inferencias que hacen quienes procesan esa estructura.

\section{Del modelo de código al modelo ostensivo-inferencial}

Hagamos un ejercicio para constatar cómo podría funcionar la topicalización en una emisión musical dada. ${ }^{11}$ Examinemos la siguiente secuencia rítmica:

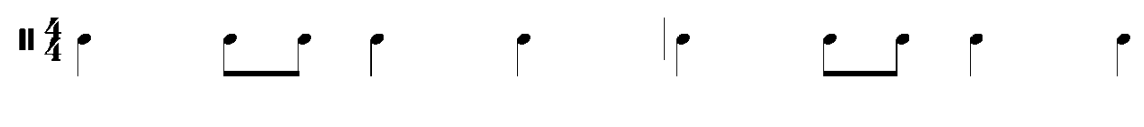

Ejemplo 5 .

Quienes manejan el código de la escritura musical concordarán en que esta emisión consiste de una serie constituida por una negra, dos corcheas y dos negras, que se repite dos veces, en un compás de 4/4. Esto describe el nivel inmanente o neutro del que habla Nattiez (1990) y se ubica en el modelo de código. Hemos decodificado de este modo los signos del texto musical. Pero según la teoría de los actos de habla de propuesta por John Austin (1998) y John Searle (2001), esto sería simplemente lo dicho, ergo, el acto locutivo o emisión. El enunciado musical de marras no aclara con propiedad qué quería decir su emisor, qué intenciones tenía, qué entiende quien recibe esta emisión, ni qué supuestos activó en él. Si se percute la secuencia de notas con el índice de la mano derecha sobre una mesa a una velocidad regular, seguramente los músicos concluirán que se trata de una fórmula rítmica muy sencilla que se le hace a un aspirante para entrar en la clase de solfeo elemental. Para hacer estas inferencias -que aparentan ser muy sencillas- necesitamos no obstante saber ya muchas cosas sobre el mundo.

\footnotetext{
${ }^{11}$ La exposición que sigue es una versión adaptada de un extracto del artículo "Algunas consideraciones adicionales sobre el ritmo y la notación del merengue" (Sans 2009).
} 
Ahora bien, si en vez de percutir la fórmula con el dedo índice de una sola mano, alternásemos sucesivamente el índice de la mano derecha con el de la izquierda en cada figura de nota, tendremos como resultado el ejemplo 6 , en el cual $d$ corresponde a derecha, $i$ a izquierda:

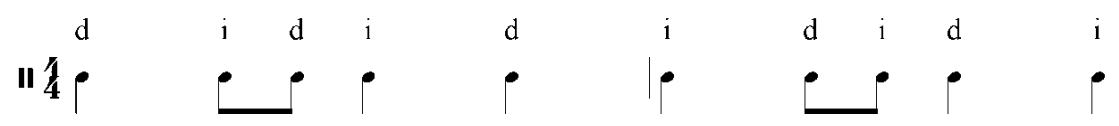

Ejemplo 6.

En el nivel textual se trata de la misma secuencia del ejemplo 5, sólo que ahora tiene una alternancia entre dos manos, definida por las letras $d \mathrm{e}$ $i$. Al ejecutar la fórmula de este modo, se activan nuevas inferencias en el emisor, quien ahora tiene la sensación de una ampliación de la frase musical, de uno a dos compases: el ejemplo 5 consiste únicamente de la repetición de la misma serie dos veces seguidas, mientras que en el ejemplo 6, hay una primera serie que comienza con el índice derecho y termina con el izquierdo, en tanto que hay otra segunda que comienza con el izquierdo y termina con el derecho, a pesar de tener los mismos signos musicales. Es importante observar que tal asimetría se está produciendo básicamente en el cuerpo del emisor, no necesariamente en su mente; y si la percusión se hace con la misma pujanza, dinámica y timbre en ambos dedos, el receptor no debería notaría ninguna diferencia sonora entre la ejecución del ejemplo 5 y la del ejemplo 6. De ser así, el receptor haría las mismas inferencias en ambas emisiones. Para visualizar mejor lo que sucede, reescribamos el trozo diferenciando cada dedo, al colocar el derecho en alto y el izquierdo en bajo, como se muestra en el ejemplo 7:

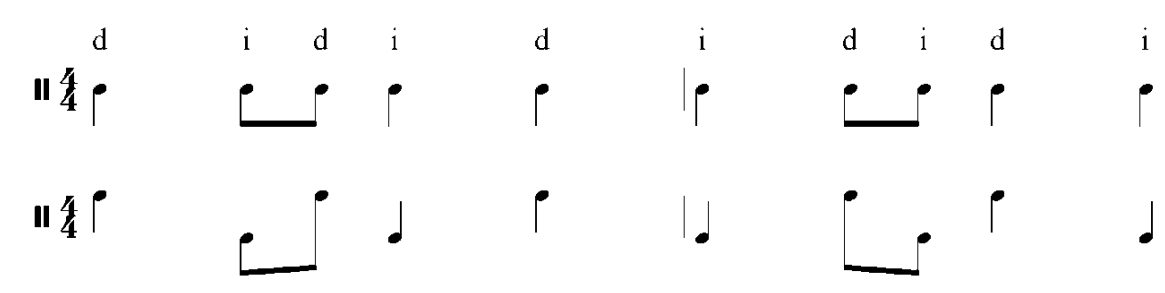

Ejemplo 7.

La alternancia gráfica del ejemplo 7 nos permite reflejar en la notación la diferencia entre la primera y la segunda serie del ejemplo 6. A pesar de seguir siendo la misma emisión del ejemplo 5, comienzan a activarse en el emisor hipótesis interpretativas más allá del enunciado mismo, más allá 
de los signos, más allá de lo dicho. Esto es, la emisión adquiere una fuerza ilocutiva (al decir de Austin) que por sí sola no tenía, que está dependiendo por entero (hasta ahora) de la intención comunicativa del emisor.

Si el receptor está no sólo escuchando, sino también viendo al emisor tocar los ejemplos 6 y 7, el estímulo visual de la alternancia entre las dos manos en la ejecución podría eventualmente llamar su atención. Siendo la emisión sonora homogénea en cuanto a dinámica y timbre, esta ostensión visual será relevante, aunque no tenga efecto en la codificación de los sonidos. Esto demuestra por qué la comunicación no depende de los signos, sino de las inferencias que haga el receptor de la ostención comunicativa del emisor.

Para hacer definitivamente ostensible la asimetría de la emisión al receptor, el emisor podría pronunciar la sílaba ti simultáneamente con cada golpe del dedo derecha, y ta con cada golpe del izquierdo. De este modo, el receptor va a captar lo siguiente:

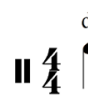

ti
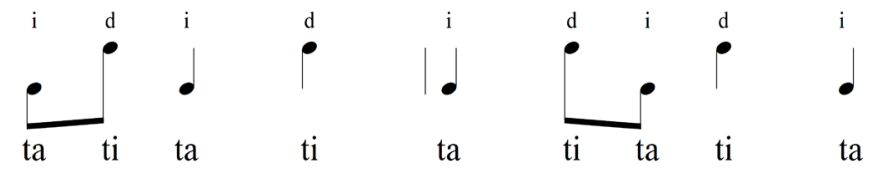

Ejemplo 8.

Introduzcamos ahora una hipótesis interpretativa que probablemente ninguno de los lectores tenía en mente al momento de hacer todos estos ejemplos, y veremos cómo a partir de la misma, el enunciado se topicaliza de inmediato. La hipótesis es la siguiente: estamos ejecutando uno de los complejos rítmicos más intrincados de la música tropical. Veamos cómo, y por qué.

Si despejamos uno solo de los dedos del conjunto, por ejemplo el derecho ( $t i$ ), que empieza con la primera figura de negra (ejemplo 9), obtendremos la siguiente emisión:

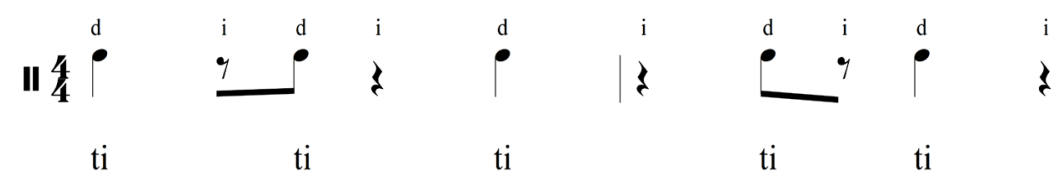

Ejemplo 9. 
Bajo esta hipótesis, nos percataremos de inmediato que del dedo derecho está haciendo una clave de son en 3-2. Esto puede sorprendernos mucho si no habíamos hecho esa inferencia antes. Pero nos sorprenderemos aún más si despejamos la mano izquierda, que empieza con la segunda figura de la serie $(t a)$ :

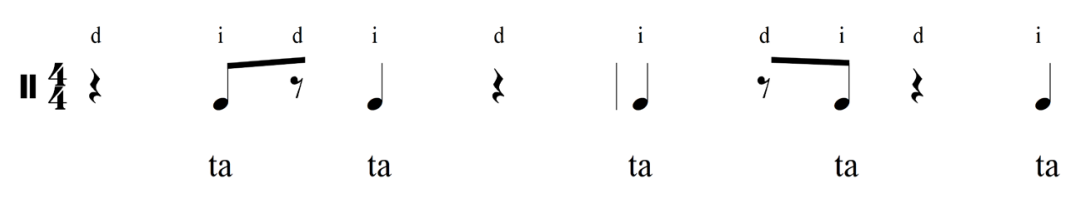

Ejemplo 10.

Bajo ese supuesto, nos percatamos de que estamos haciendo una clave de son en 2-3 (ejemplo 10). Como podemos observar, de una fórmula rítmica supremamente sencilla propuesta en la emisión musical original, derivamos por ostensión e inferencia las claves simultáneas 3-2 y 2-3, algo que se considera de suma dificultad en la música tropical. La reescritura de la emisión intercalando silencios en cada mano así nos lo muestra:

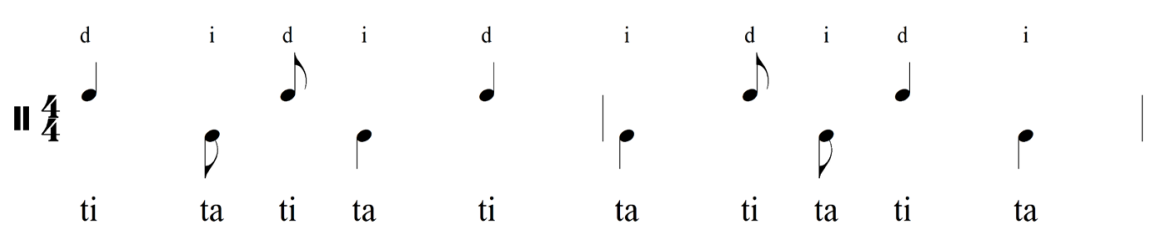

Ejemplo 11.

¿Qué ha variado ahora con respecto a cómo procesamos inicialmente el ejemplo 5, más allá de la disposición espacial de las figuras de notas? Lo que ha variado son los supuestos que emisores y receptores activaron en su interacción con este texto musical. Los signos pueden seguir siendo los mismos, pero las hipótesis interpretativas que hemos introducido han topicalizado la emisión, que por sí sola no era inicialmente más que una negra, dos corcheas y dos negras. Queda claro que sin las hipótesis, tal enunciado sería una emisión sonora que podría haber sido interpretada de otros modos radicalmente diferentes. Ahora bien, esta interpretación sólo será posible si como emisores o receptores sabemos lo que es la clave de son, de qué se trata, y a qué mundo musical nos remite. Si alguien no estuviera familiarizado con el tópico clave de son no podrá activar jamás estos supuestos. Pero ello no significa que no pueda interpretar lo escuchado, porque siempre podrá formular otras hipótesis distintas a la propuesta 
aquí, probablemente no coincidentes con las intenciones comunicativas del emisor. Esto sólo ocurrirá siempre que la ostensión logre captar su atención, le parezca relevante lo que se dice, y comience a cooperar como interlocutor en la comunicación.

\section{Conclusiones}

En el presente trabajo hemos discurrido acerca de la teoría tópica extendi$\mathrm{da}$, la cual ha resultado exitosa en la medida en que ha podido dar cuenta de algunos fenómenos musicales que hasta su formulación, no habían podido ser descritos de un modo más satisfactorio. Esto explica el éxito que ha tenido para aplicarla a algunas músicas de América Latina, como efectivamente han hecho muchos musicólogos de la región. No obstante, se pasan por alto algunos problemas que surgen al intentar ampliar el alcance de la teoría más allá del objeto de estudio original de la teoría (la música centroeuropea de finales del siglo XVIII). Para poder extender su alcance, ha tenido que sufrir reajustes y redefiniciones, que no siempre han dado los resultados esperados. Desde esta perspectiva, las críticas que los post-ratnerianos hacen a Ratner, parecen consecuencia de sus propias elecciones teóricas, y no de las deficiencias del modelo original propuesto por Ratner. El presente trabajo ensaya un enfoque diferente de la teoría tópica, que probablemente sirva para solventar algunos de estos inconvenientes presentados.

A nuestro juicio, el problema principal de la teoría tópica extendida radica en explicar los tópicos en tanto signos, que necesaria y obligatoriamente están contenidos en un texto-artefacto, y no como una función, resultado de la interacción entre texto, emisores y receptores, que es lo que podría en todo caso dar cuenta de por qué un tópico termina siendo tal. El análisis semiótico sólo permite ver signos en un texto, allí donde el análisis discursivo y pragmático ve sentidos. Es en la interacción de esas tres instancias -lo que Eco llama intentio auctoris, intentio lectoris e intentio operis-donde se constituye el tópico. Cuando los teóricos post-ratnerianos transforman la teoría tópica original en una semiótica, la adscriben a lo que aquí se ha dado por llamar el modelo de código. Ello no sería mayor problema, si no se insistiera en que la teoría tópica es una pragmática, cuando en realidad se apunta en un sentido opuesto. El modelo de código resulta insuficiente para dar cuenta de los procesos de la comunicación musical, porque presupone que el tópico musical es un signo que se codifica y descodifica, y da la competencia comunicativa como un hecho. 
Los estudios de Análisis del discurso han demostrado precisamente que la regla parece ser la incompetencia comunicativa, y es en este marco donde pretendemos comprender cómo funcionan los tópicos musicales. Algunos de los ejemplos examinados a lo largo del artículo permiten comprender las inconsistencias teóricas que emergen al aplicar la teoría tópica extendida a objetos y hechos distintos para los que fue originalmente diseñada. En tal sentido, el modelo ostensible-inferencial de Sperber y Wilson, luce más adecuado para el estudio de los tópicos musicales.

Hemos terminado el escrito con un ejercicio sencillo que permite comprender en tiempo o real cómo un enunciado musical -deliberadamente descontextualizado- va adquiriendo un sentido socialmente consensuado en la medida que emisores y receptores interactúan con el texto. El enunciado se topicaliza cuando se introducen hipótesis y supuestos interpretativos que permiten brindarle sentido a la emisión misma. La sola introducción de la variable de que la fórmula rítmica constituye una clave cruzada de son, invita seguramente a la mayoría de los lectores de este trabajo a hacer inferencias que de otro modo no se activarían, y a comprender el enunciado en un nuevo y sorprendente contexto, es decir, con base en otros supuestos de los que inicialmente se hicieron. Estos supuestos son las inferencias que hacen emisores y receptores respecto del enunciado, y funcionan en la medida en que se comparten socialmente. Sin embargo, el hecho de que las inferencias no sean totalmente compartidas, no significa que la comunicación no se produzca. Incluso en el caso de que no se compartan en absoluto, siempre se pueden producir otras inferencias que procuran darle sentido a los enunciados, porque si la ostensión comunicativa luce relevante y se activa el principio de cooperación, los interlocutores harán esfuerzos por comunicarse, independientemente de sus competencias a este respecto. 


\section{Bibliografía}

» Agawu, K. (2012). La música como discurso: aventuras semióticas en la música romántica. Buenos Aires: Eterna Cadencia.

» Agawu, K. (1991). Playing with Signs: A Semiotic Interpretation of Classic Music. New Jersey: Princeton University Press.

" Austin, J. L. (1998). Cómo hacer cosas con palabras. Barcelona: Paidós.

» Bolívar, A. (1998). Discurso e interacción en el texto escrito. Caracas: Consejo de Desarrollo Científico y Humanístico de la Universidad Central de Venezuela.

»Calsamiglia, H. and A. Tusón. (1999). Las cosas del decir. Manual de análisis del discurso. Barcelona: Ariel.

»Corrado, O. (2017). Ideologemes in Search of Topics: Argentine Music During the Peronist Decade. Revista Portuguesa de Musicologia, 4(1),101-120.

» Eco, U. (1997). Interpretación y sobreinterpretación. Cambridge: Cambridge University Press.

»Escandell Vidal, M. V. (1996). Introducción a la pragmática. Barcelona: Ariel.

» Fallarero Valdivia, C. (2018). Los villancicos de Juan Paris (1759-1845): Contexto y análisis musical. Revista de Musicología, 41(2, Julio-Diciembre), 751-758.

» Feyerabend, P. (2000). Tratado contra el método. Madrid: Editorial Tecnos.

» Grice, Paul. (2000 [1957]). Significado. En L. M. Valdés Villanueva (Comp.). La búsqueda del significado. Lecturas de filosofía del lenguaje (pp. 485-494). Madrid: Editorial Tecnos.

»Hatten, R. S. (1994). Musical Meaning in Beethoven: Markedness, Correlation, and Interpretation Advances in Semiotics. Bloomington \& Indianapolis: Indiana University Press.

»Hernández Salgar, O. (2013). El tópico de la melancolía en la música andina colombiana: semiosis del gesto cadencial ${ }^{\wedge} 7^{\wedge} 5^{\wedge} 4^{\wedge} 3$. A Contratiempo, 22(12).

»Kerman, J. (1980). How We Got into Analysis, and How to Get Out. Critical Inquiry, 7, 311-331.

»Kerman, J. (1985). Musicology. London: Fontana.

»López Cano, R. (2002). Entre el giro lingüístico y el guiño hermenéutico: tópicos y competencia en la semiótica actual. Cuicuilco, 9(25, mayo-agosto), $1-40$.

»López Cano, R. (2005). Más allá de la intertextualidad. Tópicos musicales, esquemas narrativos, ironía y cinismo en la hibridación musical de la era global. Nasarre: Revista aragonesa de musicología, 21(1), 59-76.

" McKay, N. (2007). On Topics Today. Zeitschrift der Gesellschaft für Musiktheorie, 4(1-2), 159-183. 
» Mirka, D. (2014). Introduction. En The Oxford Handbook of Topic Theory, (pp. 1-57). New York: Oxford University Press.

" Monelle, R. (2006). The Musical Topic. Hunt, Military and Pastoral. Bloomington and Indianapolis: Indiana University Press.

» Monelle, R. (2000). The Sense of Music. Semiotic Essays. Princeton, Oxford: Princeton University Press.

"Nattiez, J-J. (1990). Music and Discourse. Toward a Semiology of Music. Princeton, New Jersey: Princeton University Press.

»Piedade, A. (2011). Perseguindo fios da meada: pensamentos sobre hibridismo, musicalidades e tópicas. Per Musi, 23, 103-112.

»Piedade, A. (2013). A teoria das tópicas e a musicalidade brasileira: reflexões sobre a retoricidade na música. El oído pensante, 1(1). Recuperado de http://ppct.caicyt.gov.ar/index.php/oidopensante/article/ view/2202/45454575759450

»Plesch, M. (1996). La música en la construcción de la identidad cultural argentina: el topos de la guitarra en la producción del primer nacionalismo. Revista Argentina de Musicología, 1, 57-68.

»Plesch, M. (2008). La lógica sonora de la generación del 80: Una aproximación a la retórica del nacionalismo musical argentino. En Los caminos de la música (Europa-Argentina) (pp. 55-111). Jujuy: Editorial de la Universidad Nacional de Jujuy.

" Plesch, M. (2012). Topic Theory and the Rhetorical Efficacy of Musical Nationalisms: The Argentine Case. Proceedings of the International Conference on Music Semiotics University of Edinburgh, 26-28 October 2012, UK In memory of Raymond Monelle (pp. 328-337). Edinburgh: University of Edinburgh.

»Plesch, M. (2014). 'Una pena estrordinaria': tópicos disfóricos en el nacionalismo musical argentino. Primer Congreso de la Asociación Regional para Latinoamérica y el Caribe de la Sociedad Internacional de Musicología (La Habana, 17-24 de marzo de 2014). n.d.

»Plesch, M. (2017a). The Learned Style in Argentine Music: Topic Simultaneity and Rhetorics of Identity in the Work of Carlos Guastavino. Revista Portuguesa de Musicologia, 4(1), 121-140.

»Plesch, M. (2017b). Decentring Topic Theory: Musical Topics and Rhetorics of Identity in Latin American Art Music. Revista Portuguesa de Musicologia, 4(1), 27-32.

» Ratner, L. G. (1980). Classic Music: Expression, Form, and Style. New York: Schirmer.

»Salles, P. de T. (2017). Villa-Lobos e sua brasilidade: Uma abordagem a partir da teoría das marcaçoes (markednes) de Hatten. Revista Portuguesa de Musicologia, 4(1), 67-82.

»Sans, J. F. (2009). Algunas consideraciones adicionales sobre el ritmo y la 
notación del merengue. Akademos, 11(1-2), 117-141.

Searle, John. (2001). Actos de habla. Madrid: Cátedra.

Sperber, D. y D. Wilson. (1994). La relevancia. Madrid: Visor Dis.

»Tomlin, R. S., L. Forrest, M. M. Pu, y M. H. Kim. (2000). Semántica del discurso. En T. A. Van Dijk (Ed.). El discurso como estructura y proceso, (pp. 107-170). Barcelona: Gedisa.

»Van Dijk, T. A. (1995). Texto y contexto (Semántica y pragmática del discurso). Madrid: Cátedra.

\section{Biografía / Biografia / Biography}

\section{Juan Francisco Sans}

Es músico y musicólogo. Entre otros cargos, ha sido maestro de composición y director de la orquesta del Conservatorio Nacional de Música Juan José Landaeta de Caracas, subdirector y pianista del Coro de Ópera del Teatro Teresa Carreño de Caracas, director del Coro Sinfónico Nacional de Costa Rica, Presidente de la Fundación Vicente Emilio Sojo en Caracas, director general del Centro Nacional de la Música en Costa Rica, director de la Escuela de Artes de la Universidad Central de Venezuela, de la cual es también profesor titular. Por sus composiciones y trabajos de investigación ha obtenido diversos premios, y publicados en revistas y editoriales académicas de prestigio. Actualmente se desempeña como profesor en el Instituto Tecnológico Metropolitano de la ciudad de Medellín, Colombia. 